\title{
Comment éradiquer la rougeole en Suisse?
}

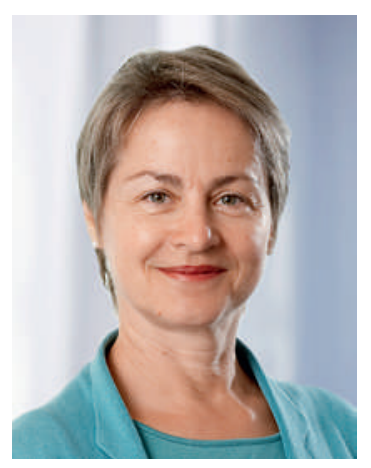

La rougeole pourrait totalement disparaître. Un vaccin efficace et éprouvé dans le monde entier existe depuis plus de 40 ans contre ce virus dont l'unique réservoir est l'être humain. De facto, toutes les conditions sont ainsi réunies pour une éradication complète de la maladie dans le monde. Pourtant, régulièrement encore, de nombreux pays - dont la Suisse - sont le théâtre de flambées de rougeole plus ou moins importantes, car ils ne sont pas en mesure d'atteindre le taux de vaccination de 95\% nécessaire à l'élimination de la maladie. Pourquoi cela?

Considérée comme une maladie infantile relativement bénigne dont on se remet facilement, la rougeole n'a, à tort, pas mauvaise réputation. Cela joue assurément un rôle. Effectivement, comparé à d'anciennes maladies de même nature, comme la polio, le danger potentiel de la rougeole est minime. Dans la plupart des cas, c'est une maladie qui se soigne sans problème mais qui peut se compliquer d'otites, de pneumonies ou, dans le pire des cas, d'encéphalites. Cependant dans une proportion tellement basse que la rougeole n'est pas prise pour ce qu'elle est: une maladie qui peut entraîner la mort! D'après les estimations de l'OMS, plus de 160000 personnes dans le monde ont succombé à la rougeole en 2008.

\section{Oublier la seconde dose chez \\ les enfants n'est pas une fatalité. \\ Un système de rappel peut aider!}

La Confédération emboîte le pas aux efforts déployés partout dans le monde et entend atteindre en 2015 le taux de vaccination de 95\% nécessaire à terme pour éradiquer la rougeole. Les personnes réfractaires à la vaccination pourront rester fidèles à leurs convictions - et bénéficier par là même de la protection que leur confèrent leurs concitoyens vaccinés.

En Suisse, qu'en est-il de l'immunité contre la rougeole? Qui n'est pas protégé? Selon toute probabilité, les personnes nées en 1963 ou avant ont contracté la maladie dans leur jeunesse. A cette époque, il n'y avait en effet aucun moyen d'échapper au virus très contagieux. Sinon, comment se présente la situation helvétique après plus de 40 ans de vaccination? Le taux de vaccination de tout le pays s'élève à $85 \%$, mais d'importantes différences cantonales subsistent. Avec des taux de vaccination de 90 à plus de 95\%, les cantons la- tins frôlent déjà l'objectif visé. La Suisse centrale en revanche et le canton d'Appenzell Rhodes-Extérieures manquent sensiblement l'objectif en affichant respectivement des taux inférieurs à 70\% et 79\%. Par conséquent, le nombre de cas recensés lors des épidémies de rougeole entre 2006 et 2009 a été beaucoup plus élevé dans ces cantons.

\section{Les vaccinations de rattrapage sont indiquées pour les adultes, plus affectés par la maladie et davantage sujets à des complications que les enfants.}

Il est encourageant de voir que le premier vaccin est inoculé à un grand nombre d'enfants. 90\% d'entre eux sont vaccinés dans les deux premières années de leur vie, jusqu'à la fin de la scolarité ce taux atteint 94\%. Mais les chiffres concernant la piqûre de rappel sont moins réjouissants. En effet, cette seconde dose indispensable à une protection efficace n'est administrée qu'à 75\% de tous les enfants, un taux nettement insuffisant. Dans ce contexte, il appartient aux médecins de jouer leur rôle: pourquoi ne pas mettre en place un système de rappel avisant simplement les parents? Pourquoi ne pas toujours inscrire le deuxième vaccin à l'ordre du jour des consultations régulières de prévention pédiatrique?

L'analyse des flambées de rougeole montre cependant aussi que de nombreux adultes et adolescents ne sont pas ou pas suffisamment vaccinés. Au cours des premiers mois de cette année, cinq personnes non vaccinées ont contracté la rougeole en Europe ou en Asie et l'ont «importée» en Suisse. De manière générale, plus affectés par la maladie, les adultes sont davantage sujets à des complications. Pour eux, une vaccination de rattrapage est donc vraiment indiquée. A cet égard, les cantons disposent de différentes possibilités d'agir, notamment dans le cadre de la stratégie nationale pour éliminer la rougeole. Les cantons faisant état d'un taux de vaccination insuffisant peuvent organiser des journées d'action avec une vaccination gratuite. Si les personnes non vaccinées sont disposées à recevoir gratuitement un vaccin et si elles sont bien informées des risques spécifiques à la maladie pour les adultes, ces journées d'action seront un succès.

Lorsque l'occasion se présente d'éradiquer une maladie qui peut provoquer la mort, nous devrions la saisir - pour notre propre protection et pour le bien de tous.

Dr Christine Romann, membre du Comité central de la FMH, responsable du domaine Promotion de la santé et prévention 